Revista Água Viva

\title{
A IXTLAMACHILIZTLI EM MALINCHE: A TRANSMISSÃO DA SABEDORIA MEXICA
}

\section{LA IXTLAMACHILIZTLI EN MALINCHE: LA TRASMISIÓN DE LA SABIDURÍA MEXICA}

Sara Lelis de Oliveira ${ }^{1}$

Resumo: O presente trabalho visa apresentar a obra literária MALINCHE (2006), da escritora mexicana Laura Esquivel, no que diz respeito à ixtlamachiliztli recriada ficcionalmente partir da interação da protagonista Malinalli com la abuela. O conceito ixtlamachitliztli, em língua nahuatl, foi traduzido por "ação de dar sabedoria a rostos alheios" e define uma forma de transmissão do conhecimento entre os mexicas (ou astecas), elite indígena dominante no período pré-hispânico antes da invasão castelhana. A narrativa, ao recuperar esse conceito na literatura, convida à uma discussão referente à decolonialidade epistemológica no contexto mexicano na qual se examina um caminho complexo em direção a um locus não eurocêntrico de conhecimento.

Palavras-chave: MALINCHE; Ixtlamachiliztli; Decolonialidade epistemológica.

Resumen: Este trabajo pretende exponer la obra literaria MALINCHE (2006), de la escritora mexicana Laura Esquivel, en cuanto a la ixtlamachiliztli recriada en literatura a partir de la interacción de la protagonista Malinalli con la abuela. En la traducción al español de México se tradujo el concepto ixtlamachiliztli, en lengua nahuatl, bajo la definición "acción de dar sabiduría a rostros ajenos", la cual especifica una forma de trasmisión del conocimiento entre los mexicas (o aztecas), élite indígena dominante en el periodo prehispánico antes de la invasión castellana. Al recuperar ese concepto, la narrativa invita a una discusión referente a la decolonialidad epistemológica en el contexto mexicano en la cual se examina un camino complejo hacia un locus no eurocéntrico de conocimiento.

Palabras clave: MALINCHE; Ixtlamachiliztli; Decolonialidad epistemológica.

\section{CONSIDERAÇÕES INICIAIS}

A obra literária MALINCHE (2006), da escritora mexicana Laura Esquivel, consiste na narração ficcional dos principais acontecimentos históricos ocorridos entre os

\footnotetext{
${ }^{1}$ Cursa o Doutorado em Estudos Literários Comparados no Programa de Pós-Graduação em Literatura (PÓSLIT) da Universidade de Brasília (UnB). Mestre em Estudos da Tradução e Bacharel em Letras Tradução - Espanhol pela mesma universidade. E-mail: saralelis@gmail.com
} 
anos 1519 e 1521 na Mesoamérica, vasta região em que parte se insere o atual México. Essa série de sucessos, historicamente conhecida como A Conquista do México, é narrada desde o locus da personagem Malinalli, recriação da figura que aparece nos discursos historiográficos mexicanos do século XX sob o epíteto Malinche. A alcunha designa conotações pejorativas de traição e adultério, pois na então consumada Conquista a personagem atuou de maneira favorável aos castelhanos como intérprete de Hernán Cortés, líder de uma das empresas europeias que invadiram o território mesoamericano com fins de dominação política e religiosa a partir de 1492. No ofício de intérprete, a personagem colaborou diretamente com a queda e o massacre dos mexicas - povo que dominava quase todo território mesoamericano desde 1325 (SANTOS, 2002, p. 74) - e indiretamente com a carnificina de outros povos. O papel da intérprete na inauguração do período colonial mexicano é deveras discutido até os dias correntes, suscitando discussões tais como "traiu ou não traiu a pátria?". Sob a denominação de Malinalli, a perspectiva histórica recomposta em MALINCHE dilui as polêmicas engendradas pelo título despectivo. Nessa narrativa, sua colaboração favorável aos estrangeiros fundamenta-se na reconstrução histórico-literária da estrutura de vida e de poder no universo préhispânico da personagem.

$\mathrm{Na}$ referida reconstrução histórico-literária evocada pela obra MALINCHE, na qual se entrelaçam a conjuntura do período pré-hispânico e a vida biográfica de Malinalli, a que se faz central no âmbito deste trabalho diz respeito à formação intelectual da protagonista. Entre os historiadores e estudiosos de sua biografia são inúmeras as discrepâncias sobre sua origem e lugar de nascimento, estrato social, data e razões de sua morte, entre outros aspectos biográficos (HERNÁNDEZ GONZÁLEZ, 2002, p. 181). A narrativa literária, porém, reconstitui para ela uma vida anterior à escravidão consoante à função desempenhada no processo da Conquista. Ao ser uma das dezenove escravas dadas de presente a Hernán Cortés como honraria pela vitória em uma batalha contra indígenas (ESQUIVEL, 2006, p. 65), Malinalli destacou-se por sua retórica, pelo profundo conhecimento da cultura que a empresa castelhana objetivava destruir e, principalmente, por falar três idiomas: o nahuatl, o maia e, com a chegada dos estrangeiros, o castelhano. Cortés já não via eficiência alguma nas negociações intermediadas por seu intérprete anterior, o soldado castelhano Jerónimo Aguilar, e constatou que os atributos da indígena seriam mais promissores para alcançar o domínio do território preterindo-se dos artifícios bélicos (ESQUIVEL, 2006, p. 41). As habilidades 
da personagem derivam-se tanto de sua origem forjada na narrativa quanto de sua condição como escrava. Em MALINCHE, Malinalli pertence à nobreza indígena (pipiltin) (ESQUIVEL, 2006, p. 11), fato literário que justifica toda sua sabedoria, retórica e o domínio do nahuatl, ao passo que sua experiência territorial e o aprendizado do maia e do castelhano se devem à sua peregrinação impulsionada pela escravidão.

A origem nobre de Malinalli recriada na obra literária inscreve a protagonista nos padrões da intelectualidade da elite mexica (pipiltin) cujos descendentes recebiam os ensinamentos que os tornariam dignos cidadãos mexicas ou em casa pelos pais, avós e parentes, ou nas calmécac (centros de educação superior) pelos tlatolmatinime (professores da palavra) (LEÓN-PORTILLA, 2014, p. 199). A transmissão do conhecimento entre os mexicas baseia-se na ixtlamachiliztli: do nahuatl, "ação de dar sabedoria a rosto alheios" (LEÓN-PORTILLA, 2014, p. 193, tradução de León-Portilla). Trata-se de uma forma de apreensão do conhecimento baseada no rosto e no coração do aprendiz, forma esta de uma lógica epistemológica fora do modelo eurocêntrico de conhecimento. Neste sentido, a narrativa recupera essa forma de transmissão do conhecimento ao recriar ficcionalmente a avó paterna de Malinalli, uma sábia anciã mexica que se encarrega de transmitir à neta "seu coração e sabedoria" (ESQUIVEL, 2006 , p. 23, tradução nossa), instituindo-a com a sabedoria tal como os filhos dos membros da nobreza. O status social da personagem é invertido após o abandono da mãe e seu desejo de constituir outra família em consequência da morte do pai e da avó de Malinalli.

No contexto literário em questão, quase quinhentos anos após a ruptura do mundo pré-hispânico, sem dúvida se traz à tona tanto a cultura pré-hispânica quanto uma forma de transmissão do conhecimento alheios ao modelo ocidental que deslegitima todo saber não-eurocêntrico. MALINCHE, neste sentido, abre uma discussão referente à decolonialidade epistemológica por reconstruir em sua narrativa um saber que dá a conhecer seu rompimento causado pela transição do pré-moderno para o moderno. A compreensão de mundo apresentada pauta-se no próprio espaço e tempo ao qual a narração se refere, proporcionando um locus epistemológico que lhe é próprio, mas não autêntico. Assim como propõe os estudos decoloniais, trata-se, em efeito, de uma reconstrução. No entanto, colocamos em questão o contexto mexicano do período colonial em que se recuperou grande parte das tradições do povo mexica. A ação foi possível sobretudo mediante o trabalho de Bernardino de Sahagún, um dos frades 
católicos castelhanos que salvaguardaram grande parte do conhecimento pré-hispânico ao compilar e orientar a transcrição do nahuatl oral para o castelhano escrito em alfabeto latino pelos sobreviventes e descendentes indígenas e, posteriormente, parafraseá-los em língua castelhana. A missão do frade, com esse propósito, serviu como base para a difusão do universo pré-hispânico, pois uma das formas de se acessar a este mundo ocorre por intermédio de suas paráfrases em língua castelhana, como é o caso da ixtlamachiliztli. $\mathrm{O}$ processo está nitidamente implicado pela cosmovisão ocidental que, hibridada com o pensamento indígena, conformou a cultura tradicional mexicana cujo cerne nitidamente se estrutura em uma cosmovisão pré-hispânica desde a ótica ocidental. Neste sentido, lançamos neste trabalho a seguinte pergunta: em que medida se pode pensar a decolonização epistemológica no contexto mexicano haja vista um dos pontos de partida em que se deu a conhecer o pensamento indígena pré-hispânico?

\section{A ixtamachiliztli em MALINCHE}

A aproximação ao conceito em língua nahuatl ixtlamachiliztli resulta do seguinte trecho referente à fala da avó de Malinalli logo no início da narrativa: "Dizem que durante esse tempo, muitas vezes esteve a ponto de morrer, mas rapidamente se recuperou dizendo que não poderia partir antes de ver quem herdaria seu coração e sua sabedoria" (ESQUIVEL, 2006, p. 23, tradução nossa). A personagem estava prestes a nascer e a avó não se deixava entregar à morte afirmando a importância que teria em sua vida ao longo de muitos anos. A preocupação da avó em transferir à neta "seu coração e sabedoria" advém do ideal de "educação"2 na cultura nahuatl pré-hispânica. A transmissão da sabedoria e sua relação com o coração diz respeito à concepção de formação do cidadão mexica. O coração do indivíduo, por sua vez, correlaciona-se com seu rosto. Trata-se de que na cultura nahuatl a fisionomia de um indivíduo corresponde ao que há em seu interior. Em um dos textos compilados em nahuatl pelo frade católico Bernardino de Sahagún, fruto de suas entrevistas com os indígenas sobreviventes, podemos identificar o primeiro vínculo, entre rosto e coração:

\section{El hombre maduro:}

\footnotetext{
${ }^{2} \mathrm{O}$ termo educação figura entre aspas em razão da incerteza que há, segundo os estudos sobre referida cultura, de um conceito preciso do hoje se designa como educação (LEÓN-PORTILLA, 2014, p. 191).
} 
corazón firme como la piedra, corazón resistente como el tronco de un árbol; rostro sabio, dueño de un rostro y un corazón, hábil y comprensivo

(LEÓN-PORTILLA, 2014, p. 193, tradução de León-Portilla)³.

O segundo vínculo, entre o coração e a sabedoria, é resultante da fisionomia do rosto como expressão do que há no coração. Ser um homem sábio, portanto, significa ser um homem que possui na fisionomia do rosto a sabedoria presente no coração, características essas que não são inatas senão transferidas pelos sábios (tlamatinime) anciãos e professores da palavra (tlatolmatinime), conforme se atesta pelo trecho seguinte:

\author{
Maestro de la verdad, \\ no deja de amonestar. \\ Hace sabio los rostros ajenos, \\ hace a los otros tomar una cara, \\ los hace desarrollarla \\ (LEÓN-PORTILLA, 2014, p. 193, tradução de León-Portilla) ${ }^{4}$.
}

A transmissão da sabedoria ou ixtlamachiliztli ("ação de dar sabedoria a rostos alheios”) é somente um dos conceitos em nahuatl entre os vários outros que expressam as maneiras de educar um cidadão. No caso do conceito em questão, os ensinamentos, provenientes da ação da ixtlamachiliztli, abarcavam tanto a maneira com a qual os indivíduos deveriam viver, obedecer às pessoas, respeitá-las, entregar-se ao que é justo ou evitar o que é injusto quanto o mais elevado conhecimento da cultura nahuatl (LEÓN-

\footnotetext{
${ }^{3} \mathrm{O}$ trecho em nahuatl compilado por Sahagún está no Códice Matritense de la Real Academia, edição de Del Paso y Troncoso, vol. III, fol. 109 v. A seguinte tradução para o português é nossa e também em todos os outros casos que se apresentarão neste trabalho quanto à tradução do nahuatl para o espanhol mexicano por León-Portilla.

O homem maduro:

coração firme como a pedra,

coração resistente como o tronco de uma árvore;

rosto sábio

dono de um rosto e um coração,

hábil e compreensivo.

Não entraremos aqui, embora haja ciência, na ampla discussão que a tradução do nahuatl para o espanhol suscita no trabalho do historiador mexicano Miguel León-Portilla, tema que também é objeto de nosso estudo.

${ }^{4}$ Maestro da verdade, não deixa de advertir.

Faz sábio os rostos alheios,

faz os outros adquirirem uma cara, os faz desenvolvê-la.
} 
PORTILLA, 2014, p. 195). As crianças e jovens mexicas recebiam a sabedoria ou em casa, pelos pais e parentes, ou nas calmécac (centros de educação superior), lugar ao qual todos os pais eram obrigados a enviar seus filhos desde os seis anos de idade (LEÓNPORTILLA, 2014, p. 204) a fim de serem formados segundo a concepção de um indivíduo sábio. Só assim esses pais, nobres indígenas, poderiam ocupar seu posto na comunidade. A afirmação sustenta-se pelo trecho a seguir, também parte do material compilado por Sahagún:

\author{
Cuando un niño nacía, \\ lo ponían sus padres \\ $o$ en el calmécac $o$ en el telpochcalli. \\ Prometían al niño como un don, \\ Y lo llevaban o al calmécac \\ Para que llegara a ser sacerdote, \\ $o$ al telpochcalli, \\ para que fuera un guerrero \\ (LEÓN-PORTILLA, 2014, p. 204, tradução de León-Portilla) ${ }^{5}$.
}

A recriação ficcional da transmissão da sabedoria mexica em MALINCHE não se difere das pesquisas historiográficas sobre a cultura nahuatl, mas apenas se ajustam às condições postuladas para Malinalli. Na narrativa, a avó se encarrega de transmitir os ensinamentos da neta por pressentir não só que a morte se aproximava, mas principalmente que a menina "estava destinada a perder tudo, para encontrar tudo" ESQUIVEL, 2006, p. 11, tradução nossa) em alusão ao que aconteceria em sua vida nos próximos anos. Por esse motivo, mesmo antes dos seis anos de idade a avó ensinava-lhe princípios dentro de casa:

Malinalli era uma criança de apenas quatro anos de idade, mas com grande sabedoria, perguntou a avó:

-Quem teve a ideia de criar jarros para a água?

-A própria água teve a ideia.

-E para quê?

- Para poder repousar em sua superfície e assim poder nos contar os segredos do universo. Ela se comunica conosco em cada poça, em cada lago, em cada rio; tem diferentes formas para se vestir de gala e

\footnotetext{
${ }^{5}$ Quando uma criança nascia, era colocada por seus pais, ou na calmécac ou no telpochcalli. Prometiam à criança como um dom e a levavam ou à calmécac, para que chegasse a ser um sacerdote, ou à telpochcalli, para que fosse um guerreiro.
} 
apresentar-se diante de nós sempre nova. A piedade do deus que habita na água inventou os recipientes onde, ao mesmo tempo que alivia nossa sede, fala conosco. Todos os recipientes onde a água está nos lembram que deus é água e é eterno ${ }^{6}$ (ESQUIVEL, 2006, p. 25, tradução nossa).

A parte do que era necessário na formação de um indivíduo mexica, tais como simples tarefas relacionadas às responsabilidades e obrigações de cada um, destacam-se as formas de transmissão e aprendizado pré-hispânicas também no que se refere à intelectualidade, imprescindível na formação dos corações e rostos sábios. Essas exigiam mais complexidade para serem transmitidas. A transmissão baseava-se no cântico pelos sábios dos cantares ou hinos divinos, nas leituras das pinturas dos códices e nas récitas de mitos, lendas e poemas dos mais famosos poetas. Sua expressão, além disso, ocorria mediante uma linguagem especial, a tecpillatolli (expressão cuidadosa dos sábios e poetas) (LEÓN-PORTILLA, 2014, p. 200). Esse tipo de linguagem diferencia-se da macehuallatolli ou forma de falar do povo, utilizada não entre os pipiltin (nobreza indígena da qual provinha Malinalli), mas entre os macehualtin, população simples que por séculos vinha sendo subjugada pela nobreza (SANTOS, 2002, p. 73). A apreensão dos ensinamentos, por sua vez, ocorria pela memória ou pelos exercícios de narração solicitados no intuito de aprender a retórica e talvez tornar-se, futuramente, um grande poeta-narrador (LEÓN-PORTILLA, 2014, p. 201-202).

Na narrativa literária, o narrador afirma que, graças à avó, a linguagem de Malinalli era precisa, ampla e ordenada. Verifica-se claramente as formas de transmissão e aprendizado da cultura nahuatl pela avó e neta, respectivamente:

Desde muito cedo havia se encarregado de ensinar Malinalli a desenhar códices mentalmente para que exercitasse a linguagem e a memória. "A memória", lhe disse, "é ver desde o interior. É dar forma e cor às palavras. Sem imagens não há memória". Depois pedia à menina que desenhasse em um papel um códice, ou seja, uma sequência de imagens que narrassem algum acontecimento. Podia ser um fato real ou imaginário. A menina passava longas horas desenhando e, à noite, a avó

\footnotetext{
${ }^{6}$ Trecho original: Malinalli era una niña de sólo cuatro años de edad, pero con gran sabiduría, y le preguntó a la abuela:

- ¿A quién se le ocurrió que hubiera jarros para el agua?

- Al agua misma se le ocurrió.

- ¿Y para qué?

- Para poder reposar en su superficie y así poder contarnos los secretos del universo. Ella se comunica con nosotros en cada charco, en cada lago, en cada río; tiene diferentes formas para vestirse de gala y presentarse ante nosotros siempre nueva. La piedad del dios que habita en el agua inventó los recipientes donde, al tiempo que alivia nuestra sed, habla con nosotros. Todos los recipientes donde el agua está nos recuerdan que dios es agua y es eterno.
} 
pedia a Malinalli que narrasse seu códice antes de dormir (ESQUIVEL, 2006, p. 36, tradução nossa) ${ }^{7}$.

O papel da avó na educação de Malinalli também decorre do ideal de feminilidade na cultura nahuatl (cihuáyotl), no qual as mulheres deveriam não só saber cuidar das tarefas domésticas, dos filhos, como também possuir uma esmerada educação e uma excelente retórica (LEÓN-PORTILLA, 2014, p. 304). Na narrativa literária, Malinalli é reconstruída por todos os preceitos da cultura nahuatl estipulada pela nobreza. Seu porte e expressão chamaram a atenção dos soldados castelhanos: "Claramente Malinalli se sobressaía entre as demais escravas, caminhava com segurança, era desenvolta e irradiava senhorio", mas também era "inteligente e bela. Presta para obedecer e servir" (ESQUIVEL, 2006, p. 57, tradução nossa).

No diálogo entre a obra literária MALINCHE e a obra de Sahagún pode-se observar quanto à ixtlamachiliztli que sua apreensão e sua constituição como patrimônio cultural mexica ocorreu sobretudo pelo trabalho de compilação dos manuscritos em língua nahuatl e suas paráfrases em língua castelhana pelo frade em sua obra Historia general de las cosas de Nueva España ${ }^{8}$. O conteúdo cultural transmitido por Sahagún dos testemunhos indígenas em castelhano, meio pelo qual se pode acessar à língua nahuatl, distam sobremaneira da cosmovisão ocidental aplicada nos países colonizados. Significa que o locus epistemológico é completamente distinto. No entanto, questionamos se o caráter explicativo da cultura indígena não é feito de maneira ocidentalizada, a partir de comparações com as culturas inscritas no locus ocidental, como se pode observar no conceito cihuáyot (ideal de feminilidade). Além disso, a difusão da cultura mexica no século XX pelos estudos do historiador mexicano León-Portilla também parte de uma compreensão desde o locus ocidental do conhecimento, como se constata em sua maneira de explicar a ixtlamachiliztli pelo conceito da "paideia” grega (LEÓN-PORTILLA, 2014, p. 190).

\footnotetext{
${ }^{7}$ Desde muy temprana edad, se había encargado de enseñarle a Malinalli a dibujar códices mentales para que ejercitara el lenguaje y la memoria. «La memoria», le dijo, «es ver desde dentro. Es dar forma y color a las palabras. Sin imágenes no hay memoria». Luego le pedía a la niña que dibujara en un papel un códice, o sea, una secuencia de imágenes que narraran algún acontecimiento. Podía ser un hecho real o imaginario. La niña pasaba largas horas dibujando y, por la noche, la abuela le pedía a Malinalli que le narrara su códice antes de dormir. De esta manera era como ellas jugaban. La abuela se divertía mucho descubriendo la imaginación y la inteligencia que su nieta tenía para interpretar las imágenes de un lienzo. ${ }^{8}$ A obra Historia general de las cosas de Nueva España é um resumo em língua castelhana dos dois principais documentos por ele compilados em língua nahuatl, o Códice Florentino e o Códice Matritense de la Real Academia (LEÓN-PORTILLA, 1978, p. xxiv).
} 
O eixo de análise de discussão da obra literária MALINCHE no que se refere à transmissão do conhecimento entre os cidadãos mexicas, conhecimento este recuperado e parafraseado em língua castelhana desde o ponto de vista ocidental no século XVI, abre caminho para refletir o contexto epistemológico mexicano na esfera decolonial. Seria possível a decolonialidade no contexto mexicano tendo em vista uma jornada histórica de construção do pensamento indígena com base na cosmovisão ocidental?

\section{A decolonialidade epistemológica no contexto mexicano}

$\mathrm{O}$ conceito de decolonialidade, originalmente em inglês "decoloniality" e em espanhol "decolonialidad" resulta das reflexões de um grupo de estudos inserido no debate da modernidade/colonialidade latino-americana. Seus membros, de distintas nacionalidades, ramificam a temática nos seguimentos políticos, sociais e culturais, mas o princípio que rege o conceito é a epistemologia. A expressão decolonialidade, à diferença da expressão descolonialidade, busca desfazer a "suposição de certos discursos acadêmicos e políticos [...] de que agora vivemos em um mundo descolonizado e póscolonial"" (CASTRO-GÓMEZ e GROSFOGUEL, 2007, p. 13). A decolonialidade afirma que o fim do colonialismo tal como predominou nos séculos XVI e XVII não transformou a estrutura social de mundo do modelo centro-periferia, puramente colonial, mas deu origem à outras formas de dominação.

Presenciamos, em realidade, uma transição do colonialismo moderno à colonialidade global, processo que certamente tem transformado as formas de dominação colocadas em prática pela modernidade, mas não a estrutura das relações centro-periferia a escala mundial ${ }^{10}$ (CASTROGÓMEZ e GROSFOGUEL, 2007, p. 13, tradução nossa).

Uma das formas de dominação da persistência colonial diz respeito à manutenção da estrutura epistemológica eurocêntrica. Significa que o "fim" do colonialismo consistiu em nada mais que uma visão em direção ao colonizado desde pontos de vista ainda colonizadores. A ideia central do grupo vai de encontro às noções de pós-modernidade e pós-colonialidade, ambas complementares, pois segundo os estudiosos da

\footnotetext{
${ }^{9}$ Texto original: ... suposición de ciertos discursos académicos y políticos, según la cual, [...] vivimos ahora en un mundo descolonizado y poscolonial.

${ }^{10}$ Texto original: Asistimos, más bien, a una transición del colonialismo moderno a la colonialidad global, proceso que ciertamente ha transformado las formas de dominación desplegadas por la modernidad, pero no la estructura de las relaciones centro-periferia a escala mundial.
} 
decolonialidade define-se a modernidade como um advento da colonização. Apostam, em realidade, na transmodernidade, um conceito que consiste em uma crítica ao pósmoderno, que por sua vez também é uma noção crítica à modernidade. Mas em sentido oposto, a transmodernidade postula uma crítica à modernidade fora dos padrões eurocêntricos e imperiais de pensamento. Trata-se de atingir os objetivos da descolonização aprofundando-se em sua estrutura, o que resulta na cessação das reproduções lógicas próprias da matriz colonial do poder no mundo colonizado, isto é, trata-se de desconsiderar a cosmovisão europeia para se pensar sobretudo os contextos da América Latina, um epíteto impregnado de eurocentrismo.

Neste sentido, os estudos decoloniais propõem, ademais da luta contra os domínios econômicos, políticos, jurídicos e administrativos, deslocar a produção do saber do Ocidente, ainda que sejam eles articulados a favor da resistência "latino-americana" contra a dominação eurocêntrica. O objetivo do pensamento decolonial é desconstruir a forma de poder e de conhecimento instituídos, tarefa seguida da reconstrução ou emergência de outras formas de poder e conhecimento. Questiona-se duramente os modelos eurocentristas do conhecimento, conforme afirma um dos estudiosos do grupo em entrevista, o semiótico argentino Walter Mignolo:

[...] o projeto modernidade/colonialidade é crítico tanto da direita quanto da esquerda. Posiciona-se frente às ideologias imperiais, racistas, sexistas e não coincide com a esquerda marxista. Isto é: o pensamento decolonial é desobediente tanto epistêmica como politicamente ${ }^{11}$ (MIGNOLO, 2007, p. 195, tradução nossa).

A crítica ao eurocentrismo epistêmico fundamenta-se em uma postura da colonialidade do poder em que se supõe ser o conhecimento europeu o único legítimo. Os outros conhecimentos, referentes a todos quantos não fossem europeus, foram considerados inferiores e míticos em razão de seu caráter não-científico segundo os padrões ocidentais. No entanto, não se deve entender a visibilidade dada pelos estudos decoloniais aos outros conhecimentos como "uma missão de resgate cultural autêntico" (CASTRO-GÓMEZ e GROSFOGUEL, 2007, p. 20), pois o primeiro passo para o decolonialismo é dar a conhecer a transição entre os mundos pré-moderno e moderno no

\footnotetext{
${ }^{11}$ Texto original: [...] el proyecto modernidad/colonialidad es crítico tanto de la derecha como de la izquierda. Se posiciona frente a las ideologías imperiales, racistas, sexistas y no comulga con la izquierda marxista. Esto es: el pensamiento decolonial es desobediente tanto epistémica como políticamente.
} 
que se refere ao processo de estruturação do pensamento e produção do conhecimento. Esses processos, em si, são híbridos. Não se trata apenas da consciência da impossibilidade de um conhecimento puro, mas de que esse conhecimento pode ser ressignificado dentro das formas hegemônicas do conhecimento. Ou seja, há uma conscientização do mundo no qual estamos inseridos: a descolonização é praticamente impossível e, portanto, a colonialidade segue persistindo no âmbito da epistemologia. A perspectiva da decolonialidade, no entanto, pretende uma luta contínua por transcender historicamente a colonialidade ao modificar paulatinamente o sistema-mundo vigente no que se refere ao pensamento crítico. O decolonialismo postula uma forma de compreender o mundo, isto é, uma epistemologia que parte de uma realidade colonizada que recupera seus valores anteriores a estruturação do pensamento eurocêntrico.

Não de significa, de maneira alguma, que o retorno ao passado "tal como ele realmente foi" (BENJAMIM, 2012, p. 243), e tampouco um decolonialismo universal. O projeto de recuperar o passado genuíno dos países que atravessaram o período colonial é puramente eurocêntrico, como se pode ver no México no século XIX (HERNÁNDEZ GONZÁLEZ, 2002, p. 89), e ao mesmo tempo ignora as diferentes colonizações em razão do fluxo histórico pré-hispânico, distinto em cada um dos países. O decolonialismo tenciona uma reconstrução da memória sobrevivente dos massacres europeus, no caso do século XVI, identificando elementos pelos quais se pode pensar o presente com vistas ao futuro.

A reflexão pautada pelos estudos decolonais apresenta uma ótica pertinente para compreender a obra literária MALINCHE no que se refere à ixtlamachitliztli ("a ação de dar sabedoria à rostos alheios"). Isso porque, conforme apresentamos, as tradições indígenas mexicas compõem o patrimônio cultural mexicano mediante o trabalho missionário do frade católico Bernadino de Sahagún. Sua tarefa consistiu, inicialmente, em identificar nas tradições indígenas pré-hispânicas seus males espirituais e todo tipo de idolatria (LEÓN-PORTILLA, 2013, p. 2). No entanto, ao imiscuir-se na cultura mexica, Sahagún notou que muito daquele conhecimento poderia ser preservado em razão de sua consistência e beleza linguística. Seu trabalho, a partir de então, adotou um caráter humanista no qual não se destruiria o que lhe parecesse valoroso. Um dos conhecimentos mexicas que se manteve preservado foi a sabedoria derivada das relações entre pais e filhos, anciãos e netos, sábios e aprendizes. Para tanto, Sahagún entrevistou os descendentes indígenas sobreviventes e compilou seus testemunhos em um de seus doze 
livros que integram a obra intitulada Códice Florentino, principal meio de acesso às tradições pré-hispânicas após a ruptura do universo indígena. O conteúdo do livro foi reconstruído por intermédio da transcrição para o nahuatl escrito em alfabeto latino das entrevistas, as quais Sahagún posteriormente, parafraseou em língua espanhola, meio pelo qual se acessou à língua nahuatl.

A tarefa do missionário evidencia o propósito decolonial de ressignificação do conhecimento dentro das formas imperantes, porém atesta que os rastros do passado préhispânicos foram transmitidos desde uma perspectiva ocidentalizada. A conclusão pautase, por exemplo, nas "deidades" indígenas traduzidas como "deus", término presente tanto na narrativa literária quanto na obra de Sahagún. Além disso, conforme nos mostra a obra literária MALINCHE, os conceitos de ixtlamachitliztli e cihuyótl moldam-se em estruturas de conhecimento e padrões de feminilidade bastante próximos à epistemologia ocidental. Nosso argumento não se fundamenta no problema da similaridade, mas no fato de que o acesso ao conhecimento pré-hispânico haja ocorrido mediante as paráfrases do frade Sahagún. É neste sentido que nossa pergunta sobre a possibilidade de deslocamento do locus epistemológico dominante se coloca no âmbito desse trabalho. Tratamos não de resolver o questionamento, mas de lançá-lo de maneira a refletir a decolonialidade no contexto mexicano tendo em vista as questões levantadas.

\section{CONSIDERAÇÕES FINAIS}

O presente trabalho objetivou colocar em questão a decolonialidade epistemológica no contexto mexicano com base na análise da obra literária MALINCHE quanto à ixtlamachitliztli (do nahuatl "a ação de dar sabedoria a rostos alheios"). A narrativa literária recupera na recriação ficcional da chamada Conquista do México a sabedoria mexica e a forma de transmissão do conhecimento entre essa elite que dominou parte do território mesoamericano antes da invasão castelhana no final do século XV. O resgate de ambos os elementos pré-hispânicos ocorre via a personagem Malinalli, popularmente conhecida no México como Malinche, pois sua recriação biográfica como uma descendente da nobreza mexica (pipiltin) é o eixo para se realizar uma reconstrução histórico-literária que se centra no espaço e no tempo anterior à colonização. Para tanto, cria-se na narrativa a figura da avó, personagem que sustenta a ixtlamachiliztli através dos diálogos com a neta Malinalli em que são transmitidos para ela toda a sabedoria, a 
retórica e o conhecimento das tradições mexicas. Neste sentido, a obra literária mostra-se bastante sábia em razão do estudo historiográfico realizado para essa reconstrução da história na literatura.

A referência principal de MALINCHE é a obra do frade católico espanhol Bernardino de Sahagún, quem compilou e parafraseou para o castelhano os manuscritos escritos em língua nahuatl dos sobreviventes e descendentes indígenas sobre as antigas tradições. Esse trabalho, por sua vez, é revisitado pelo historiador mexicano Miguel LeónPortilla e seus estudos sobre a obra de Sahagún são evidentes na recuperação e recriação do universo indígena na obra literária. A problemática colocada no âmbito deste trabalho diz respeito à forma de apreensão do conhecimento das tradições mexicas baseada na obra Historia general de las cosas de Nueva España, pois um dos acessos ao passado mexicano acerca das tradições que vigoravam antes da chegada dos castelhanos ocorre pela referida bibliografia. A pergunta que este trabalho suscita, mas que ainda não alcança responder, é como pensar a decolonialidade epistemológica no contexto mexicano haja vista que o conhecimento das antigas tradições indígenas, entre elas a ixtlamachiliztli, resulta da concepção ocidentalizada imbricada nas paráfrases do frade Bernardino de Sahagún sobre a cultura indígena pré-hispânica.

\section{REFERÊNCIAS}

BENJAMIN, Walter. Sobre o conceito da História. In: Obras escolhidas I. Magia e técnica, arte e política. Tradução de Sérgio Paulo Rouanet. São Paulo: Brasiliense, 2012, p. 241-252.

CASTRO-GÓMEZ, Santiago e GROSFOGUEL, Ramón. Prólogo. Giro decolonial, teoría crítica y pensamiento heterárquico. In: El giro decolonial. Reflexiones para una diversidad epistémica más allá del capitalismo global. Bogotá: Iesco-Pensar-Siglo del Hombre Editores, 2007, p. 9-23.

ESQUIVEL, Laura. Malinche. Ed. Suma de Letras, 2006.

HERNÁNDEZ GONZÁLEZ, Cristina. Doña Marina (la Malinche) y la formación de la identidad mexicana. Ed. Encuentro Ediciones, 2002.

LEÓN-PORTILLA, Miguel. Algunas creaciones de cultura espiritual. In: Toltecáyotl: Aspectos de la cultura nahuatl. México: FCE, 1980, 10ª reimpresión, 2014, p. 139-210. 
Tocante a la "infraestructura". In: Toltecáyotl: Aspectos de la cultura nahuatl. México: FCE, 1980, 10ª reimpresión, 2014, p. 213-308.

MALDONADO-TORRES, NELSON. Walter Mignolo: una vida dedicada al proyecto decolonial. Nómadas (Col) [en linea] 2007, p. 187-195, ISSN 0121-7550. Disponível em: <http://www.redalyc.org/articulo.oa?id=105115241017> Acesso em: 20 fev. 2018.

SANTOS, Eduardo Natalino dos. Mesoamérica: história, pensamento e escrita. In:

Deuses do México indígena. Estudo comparativo entre narrativas espanholas e nativas. São Paulo: Palas Athena, 2002, p. 39-104.

Recebido em: 23 abr. 2018

Aceito em: 30 mai. 2018 